\title{
LOS ESTILOS COMPOSITIVOS Y LA MODALIDAD ORGANÍSTICA ESPAÑOLA EN EL SIGLO XVIII. UN CASO CONCRETO: EL LEVANTE ESPAÑOL
}

\author{
COMPOSITIVE STYLES AND MODALITY IN THE SPANISH ORGAN \\ MUSIC OF THE $18^{\text {TH }}$ CENTURY. A CASE STUDY: THE VALENCIA REGION
}

\author{
Alfredo Personat Remolar \\ Conservatorio Superior de Música de Castellón
}

\begin{abstract}
Resumen:
Las composiciones del presente artículo analítico, constituyen una colección representativa de obras inéditas, todas ellas de la segunda mitad del siglo XVIII y primeros años del XIX, propias del estilo eclesiástico organístico español. Los autores estudiados pertenecieron al entorno levantino, por su procedencia, o por el ejercicio de su profesión; propiamente valenciano como Ciurana, o bien meramente cercano al entorno socio-cultural valenciano, como el caso de Moreno y Polo, que prestó sus servicios musicales en la vecina catedral de Tortosa (Tarragona). Mediante una metodología que reúne la hermenéutica histórica, la musicología "comparada", y la musicología analítica, se pretende establecer un modelo para futuros estudios sobre el patrimonio musical español. El pormenor analítico se completa con el estudio comparativo de los procedimientos de autores coetáneos del resto de Europa; se han cotejado las piezas analizadas con otras composiciones coetáneas relevantes, de los autores más destacados a nivel internacional. En el cotejo realizado, nuevamente alumbran aspectos desconocidos hasta el momento, al considerarlos en paralelo y con la singularidad de la escuela organística española.
\end{abstract}

Palabras clave:

Musicología; Análisis; Ilustración; Órgano; Composición; Música española.

Abstract:

The compositions included in the present study constitute a representative collection of unpublished works, belonging to the second half of the eighteenth century and the very first years of the nineteenth, typical of the ecclesiastical style for the organ in Spain. The composer under study, belonged to the Levantine environment, because of their origins, or the exercise of their professions, as for instance the Ciurana. Other cases deals with author being close to the Valentian geographical environment, as Moreno Polo, who served in the cathedral music of Tortosa (Tarragona). Using a methodology that combines the historical hermeneutic, musicology "compared" and analytical musicology (detailed), seeks to establish a model for future studies on musical spanish heritage. The analytical detail is complemented by the comparative study with the procedures of contemporary authors from the rest of Europe have been analyzed specimens collated with other relevant contemporary compositions of the most outstanding authors internationally. In the comparison made, again illuminate previously unknown aspects, when considered in parallel with the peculiar Spanish organ school.

Key words:

Musicology; Analysis; Classical Music; Organ; Composition; Early Spanish Music. 


\section{INTRODUCCIÓN}

Las composiciones para órgano de ámbito hispánico, que se insertan en el presente estudio analítico, no han sido editadas hasta hoy, se conservan manuscritas, en cuadernillos propios del siglo XVIII de manera funcional y sumamente rústica. El fondo músico-documental pertenece al Archivo de Música de la Iglesia Arciprestal de San Jaime de Villarreal (Castellón; Comunidad Valenciana). La edición musical completa de las obras estudiadas en el presente trabajo, forma parte de un trabajo doctoral más amplio que también está a punto de ver la luz.

Los autores autóctonos estudiados, pertenecieron al entorno del levante español, bien por su procedencia, bien por el ejercicio de su profesión. Valencianos como Manuel CIURANA y ARDIOL (fl.19. sc), o cercano al entorno geográfico valenciano, como por ejemplo, el caso de Juan Domingo MORENO y POLO $(* 1711 ; \dagger 1776)$, que siendo oriundo de Aragón prestó sus servicios musicales en la catedral de Tortosa (Tarragona) -cuya diócesis, abarcaba buena parte de los territorios que posteriormente pasarían a integrar la provincia de Castellón, ya en la comunidad valenciana-.

Mediante las piezas seleccionadas para el presente estudio analítico, se pretende ofrecer una buena panorámica, tanto de los autores cuyas obras pudieron sonar en la España levantina de la segunda mitad del Setecientos e inicios del Ochocientos, así como de las formas utilizadas con mayor profusión, versos para salmos y salmodia de misas, todas ellas dotadas del carácter funcional que las hacía adecuadas para su ejecución en el templo, tanto en el marco de la liturgia propiamente dicha en la misa, o la entonación de los salmos

El estudio relativo a los procedimientos compositivos más relevantes de las obras analizadas (estilo fugado, improvisado, o dialéctico, que se combinará con las nuevas aportaciones del estilo clásico, tanto en la textura de melodía acompañada como por el nuevo sistema tonal), así como el tratamiento de la modalidad y de las indicaciones de registración, en tanto forma de estructurar tímbricamente el verso para órgano, completan la visión autóctona del órgano durante el siglo XVIII. Con vistas a proceder a la preceptiva redacción de conclusiones que den validez al estudio realizado, se ha procedido a comparar las composiciones estudiadas entre sí, así como, puntualmente mediante un procedimiento diacrónico (se han buscado unos pocos ejemplos anteriores y posteriores en el tiempo al ámbito de estudio) y sincrónico (se han cotejado las piezas analizadas con otras composiciones coetáneas relevantes de los autores más destacados a nivel internacional, particularmente del ámbito italiano, anglosajón y germánico).

\section{LOS ESTILOS COMPOSITIVOS}

Se procede en este apartado, al análisis de los estilos compositivos de dos autores del periodo ilustrado valenciano (Juan Domingo MORENO Y POLO, Manuel CIURANA Y ARDIOL), con el fin de mostrar los rasgos más representativos de los diferentes estilos y procedimientos compositivos, a la hora de anotar, en el ámbito valenciano, los versillos para órgano durante el siglo XVIII. Se han tomado al 
efecto, algunos ejemplos significativos de cada uno de los estilos cultivados sobre los que se ha procedido al análisis pormenorizado. Nótese cómo conviven en un mismo autor, e incluso en la misma salmodia (en ocasiones incluso en el mismo tono), estilos tradicionales como el contrapunto imitativo, los pasos fugados o el estilo improvisado y las cláusulas, con un estilo más propio del periodo clásico como la melodía con acompañamiento.

El análisis ha sido concebido y realizado en sus diferentes niveles (formal, motívico, armónico, contrapuntístico, textural, y de registración para órgano), desmenuzando el verso, con el fin de una mayor comprensión interna del proceso compositivo, y valoración estilística del mismo, al efecto de la comparativa y enjuiciamiento posterior con el contexto internacional.

Estilo Fugado. Juan MORENO Y POLO. (Salmodia para misas. Verso $4^{\circ}$ del Cuarto Tono):

Encontramos aquí en "puridad", el estilo tradicional organístico de pasos fugados; imitación exacta de los motivos iniciales, tres entradas (en muchas ocasiones se anotan únicamente dos), que aparecen variados a lo largo de todo el versillo, el tratamiento individualizado de las voces, la homogeneidad no jerarquizada de las voces y la disonancia preparada en cláusula.
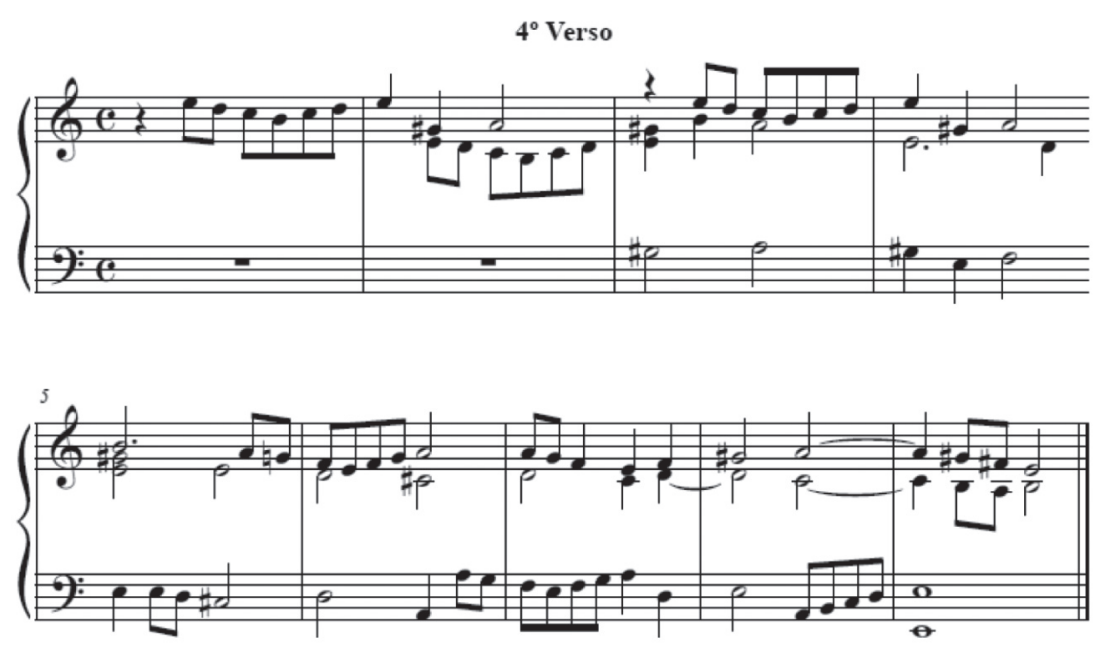

En la estructura, se aprecian dos secciones:

-c.1-5: presentación del motivo en su versión original (Mi) y cláusula.

-c.5-9: presentación del motivo variado (sobre el La, y una de las veces, por aumentación), preparación y resolución de la cláusula final (Mi).

La mano izquierda (c.8) realiza el mismo diseño que realizaba la mano izquierda en el penúltimo compás del verso anterior, pero ahora, por aumentación: 
Ejemplo
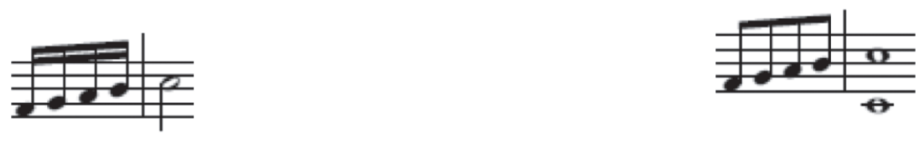

No se utiliza la figuración de corchea-2 semicorcheas, que sí había sido utilizada en los Versos $2^{\circ}$ y $3^{\circ}$.

Por lo que respecta a la textura, se aprecia un verso de carácter imitativo: el material temático expuesto se presenta durante la primera sección igual que el modelo principal.

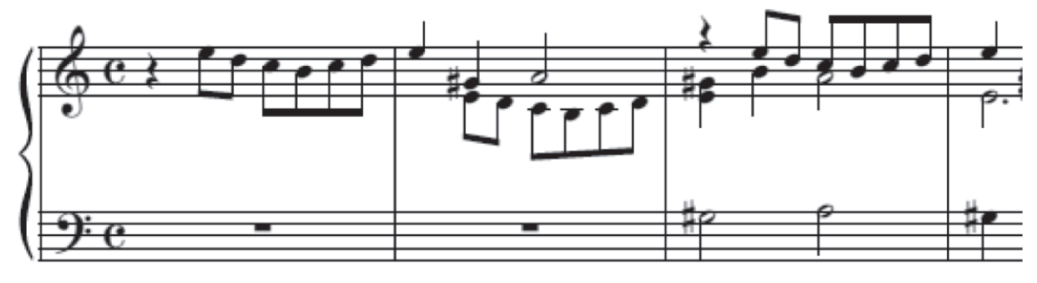

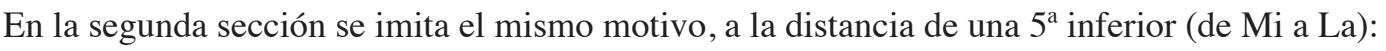

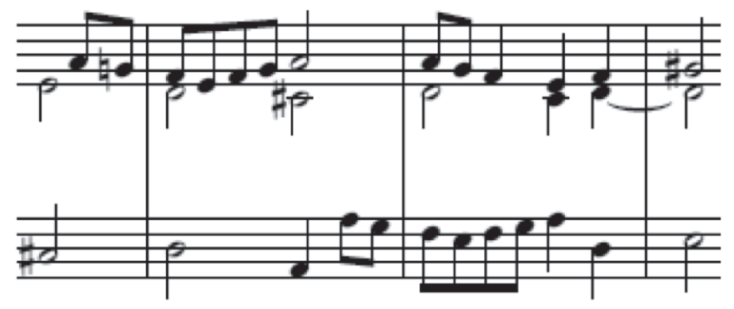

El material temático se presenta en la $1^{\text {a }}$ voz y entra "a solo" (como viene siendo habitual en los versos de carácter imitativo) extendiéndose hasta el primer tiempo del c.2; repite a una $8^{\mathrm{a}}$ inferior (en la $2^{\mathrm{a}} \mathrm{voz}$ ), hasta llegar al tiempo $1^{\circ}$ del c.3, donde repite de nuevo (en la primea voz y en la misma tesitura).

1 Por razones operativas, no se incorpora la clave en la totalidad de los ejemplos que se insertan, por lo que a menos que expresamente se indique el cambio, hay que entenderlos anotados en la clave de Sol para la mano derecha y clave de Fa para la izquierda. 
A partir del c.5, el material temático se repite sobre La, y en el tiempo $4^{\circ}$ de compás, (en vez de comenzar en el tiempo $2^{\circ}$ ). Se repite después en la mano izquierda, entrando en el tiempo $4^{\circ}$ del c.6. En el c.7, entra en el tiempo $1^{\circ}$ (mano derecha), pero con una ligera variación, a partir de la tercera corchea, y se procede por aumentación, convirtiendo las corcheas en semínimas y en mínimas.

Ejemplo: (cc.7-8, última imitación del material temático por aumentación y con segunda aumentada).

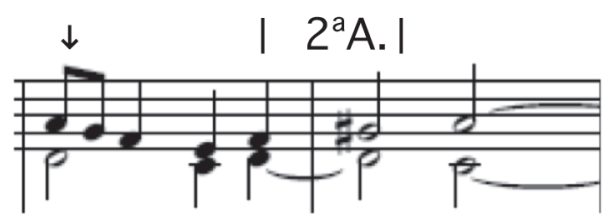

Tratamiento de la disonancia: no se anotan disonancias directas, todas son de carácter indirecto.

El tradicional estilo orgánico de pasos fugados, requiere la imitación de los motivos iniciales en las dos o tres respuestas. Los motivos se anotan variados a lo largo de todo el versillo, con un tratamiento individualizado de las voces, homogeneidad de figuraciones y la tradicional disonancia preparada en cláusula, que completa el estilo diáfano del contrapunto organístico español, frente a una mayor profusión de figuraciones rápidas y una mayor complejidad de textura en los ejemplos foráneos.

Veamos algunos ejemplos del tratamiento fugado en algunos compositores y organistas extranjeros coetáneos:

-SEGER, Josef: Fugue en Fa mineur (cc.1-4): imitación tonal de mano izquierda y pedalier (a la $5^{\text {a }}$ superior).

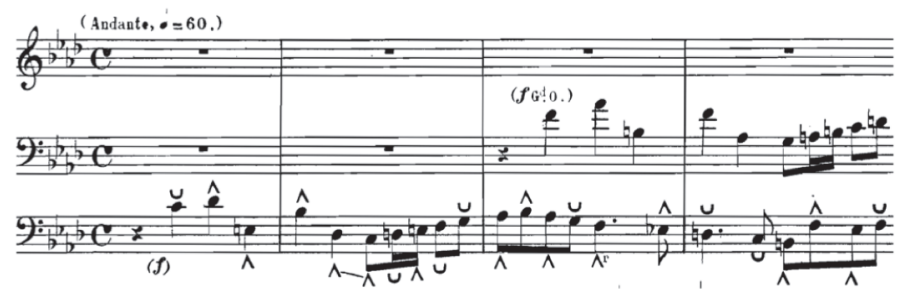


-FISCHER, Michael Gotthard: Präudium und Fugue in d (cc 8-10): imitación canónica de gran longitud y a la octava inferior.

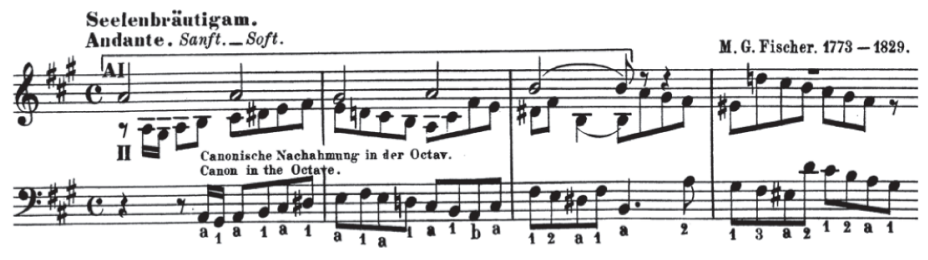

-KELLNER, Johann Peter: Ausgewälhte Orgelwerke. Präludium und Fugue in d (cc.8-10): movimiento contrario y paralelismo de consonancia.

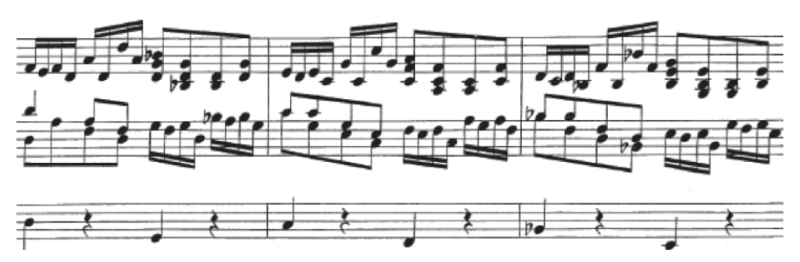

-ALBRECHTSBERGER, Johann Georg: Orgelpraeludien. Andante (cc.11-12):

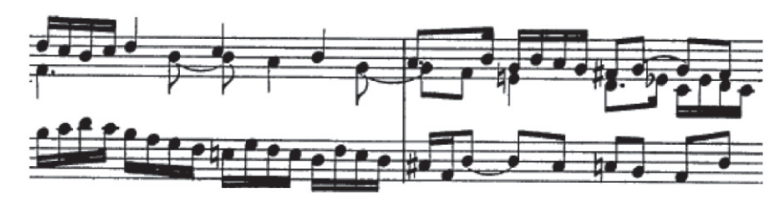

Estilo Melodía con Acompañamiento. Manuel CIURANA. (Salmodia de misas para días clásicos. Verso $8^{\circ}$ del Primer Tono):

El estilo de melodía acompañada constituye la aparición del estilo clásico como procedimiento compositivo novedoso para la escritura de órgano. Representa el empleo de un sistema "cercano" al tonal, la funcionalidad estructural, el acorde desplegado como sostén armónico, la jerarquización de las voces, y la melodía estructurada.

En el siguiente ejemplo, la figuración contrastante entre ambas manos, el intervalo melódico "funcional" de cuarta aumentada y quinta disminuida del penúltimo compás de la mano derecha, así como la alteración accidental permanente del séptimo grado, o algunos pasajes cromatizados, constituyen las novedades propias del estilo clásico y del procedimiento de melodía y acompañamiento que venía a constituirse en híbrido con la tradición orgánica española en el siglo XVIII. 

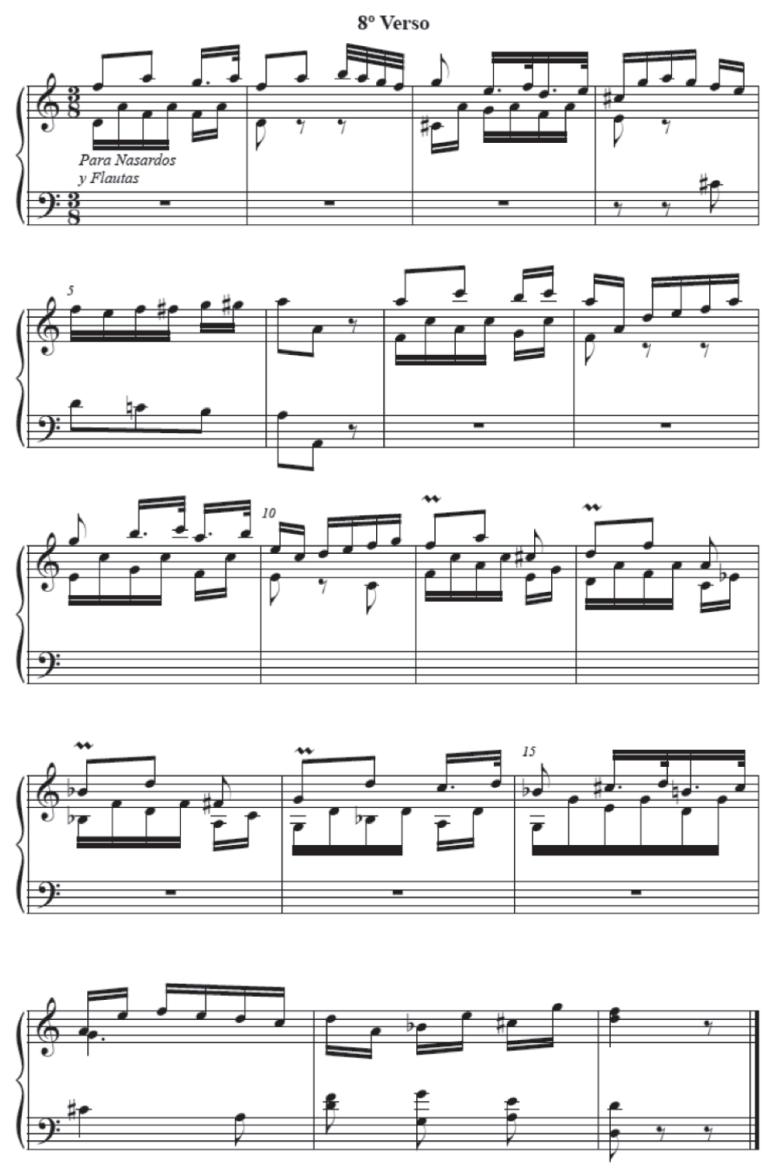

Estructuralmente, se organiza en dos secciones:

- Del c 1 al c.6: presentación de un material temático sobre el que se desarrollará todo el verso, con cláusula sobre el v grado de Re y pausa de corchea en las dos voces (que delimita claramente la primera sección, expositiva, del resto.

La voz inferior (mano izquierda) realiza un acompañamiento de 6 semicorcheas (+ 1 corchea), diseño rítmico que después aumenta (acompañamiento de 6 corcheas):

Ejemplo (c.1: acompañamiento -mano izquierda- de 6 semicorcheas):

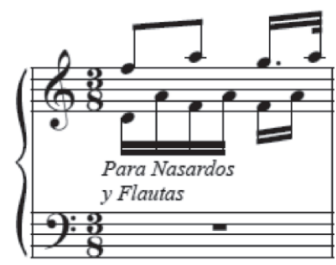


Ejemplo (cc.4-6: acompañamiento — mano izquierda - de 6 corcheas):

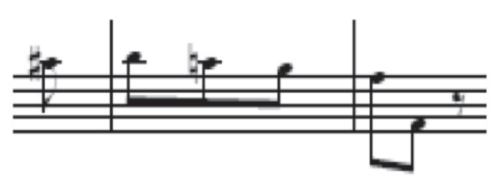

- del c.7 hasta el final: del c.7 al c.10 juega con los ritmos y figuraciones anteriormente expuestos; a partir del c.11 hay un modelo rítmico que se repite a modo de progresión hasta el inicio del c.14:

Ejemplo (c.11, "modelo" de progresión):

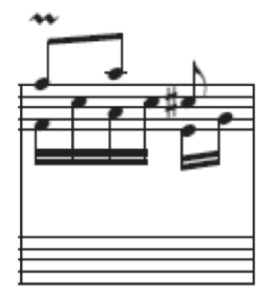

A partir del c.14 retoma las figuraciones rítmicas iniciales, pero con una variante, ya que omite la repetición del c.2, quedando de la siguiente manera: c.1 corresponde al c.14; c. 2 se omite; c. 3 corresponde al c.15; c.4 corresponde al c. 16 ; c.5 corresponde al c.17. De esta manera se crea una especie de "reexposición" de la primera sección, llegando a la preparación y resolución de la cláusula final del Primer Tono.

En realidad, el trabajo compositivo se organiza nuevamente a partir de pequeñas células (pares, o grupos de cuatro compases), a las que se alude constantemente con posterioridad, de modo que se pueden identificar las siguientes agrupaciones:

a) cc.1-4 (compuestos por dos grupos de dos compases, 1-2 y 3-4, que plantean sendos esquemas o diseños rítmicos e interválicos que se retomarán más tarde); más los cc.5-6 (episódicos, que nuevamente serán aludidos más adelante); los cc.7-10 se organizan según idéntico esquema al de los cc.1-4, de dos en dos y prácticamente con el mismo patrón rítmico;

b) cc.11-14 (agrupados igualmente de dos en dos compases, 11-12 y 13-14, pero ahora a partir de nuevo material -nos encontramos en la parte central de la pieza-, que será tratado, más que de forma imitativa, en progresión -una $3^{\text {a }}$ descendente a cada compás-);

c) cc.15-18 (nuevamente, agrupados de dos en dos compases, 15-16 y 17-18, que no suponen sino meras repeticiones de los esquemas planteados en los cc.3-4 y 5-6, respectivamente).

Se distingue de los versos anteriores del tono (que no se aportan en el presente estudio), por anotar una textura de "melodía acompañada" a 2 voces, ya que la mano izquierda parece realizar una especie de "bajo albertino". 
Ejemplo (cc.1-2):

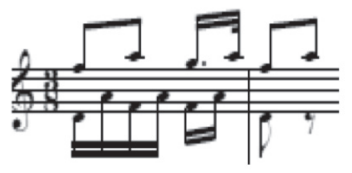

Es el verso en el que más "coincidencias" hay entre las 2 voces, es decir, que ya no se oyen de manera alternada como venía sucediendo en los versos anteriores, posiblemente siendo provocada esta mayor "densidad" sonora de manera intencionada por parte de Manuel Ciurana, dado que con este verso se acaba todo el juego o serie de versos por el Primer Tono, de manera que no sería extraño que se hubiera concebido a manera de "cierre" o broche final de la ejecución, con vistas a aportar una mayor grandilocuencia y solemnidad.

Por otra parte, volvemos a encontrar aquí un empleo meditado de las pausas, que ayudan a articular el discurso, a organizar las entradas y salidas de las voces (las imitaciones, el contrapunto) y, en fin, a ordenar el material de una manera retórica. Así, se dispone un silencio en ambas voces al finalizar el c.6, que marca una clara separación o frontera entre lo sucedido anteriormente (exposición) y cuanto viene a continuación (desarrollo, imitaciones...). Igualmente, las características agrupaciones de dos silencios de corchea (significativamente en los cc.2, 4 -en sentido inverso-, 8 y final), dividen la enunciación de diferentes diseños o motivos, mientras que, el único caso en que aparece un silencio aislado (de corchea, c.10), éste sirve para finalizar el primer apartado de la pieza ya mencionado (a) e impulsar o dar pie al inicio del siguiente (una progresión, $b$ ), sirviendo de ese modo de bisagra, hacia la parte central de la composición.

Por lo que respecta al tratamiento de la disonancia, se pueden apreciar algunas disonancias directas, en el c.1 (Fa-Sol, en el tercer tiempo, con resolución regular) y en el c.16 (en el primer tiempo, fruto del acorde de $7^{\mathrm{a}}$ sobre el $\mathrm{v}$ grado), siendo las disonancias indirectas detectables inapreciables para el oído. Sí resulta en cambio más interesante el cromatismo que utiliza en el c.5, formado por 6 semicorcheas (sobre una voz inferior en la mano izquierda, asimismo descendente, pero no por cromatismo, de manera que el cromatismo de la voz superior puede entenderse como una simple o rudimentaria ornamentación).

Ejemplo (cc.5-6: cromatismo en la mano derecha):

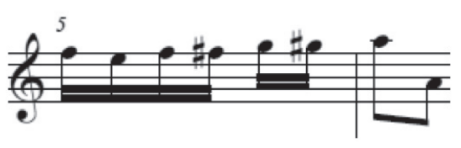


En cuanto a la Ornamentación: no aparecen acciacaturas, y únicamente utiliza cuatro mordentes (concentrados todos ellos en el pasaje central, para amenizar un poco la breve progresión de los cc.11-14). No hay signos de articulación ni dinámicas. Es decir, que aquí el compositor se muestra bastante contenido y casi podríamos decir, escueto en el tipo de escritura que desarrolla.

Por lo demás, y como indicación específica para el órgano (registración), anota que ésta sea "Para nasardos y flautados". Esta última indicación implica una sonoridad no plena, sino más bien suave, tranquila y relajada, de modo que se finalizaría la audición de todo el Primer Verso, tras varios minutos de ejecución, en un ambiente relativamente sosegado, propio del carácter o "afecto" habitualmente asociado al Primer Tono, y acaso, con la intención de enlazar la práctica de los versos salmódicos con nuevas lecturas u otros aspectos de la liturgia en que se enmarcara esta composición (una Misa, en "días clásicos", es decir, para cualquier ocasión ferial, y no necesariamente para una festividad señalada, de donde su carácter plenamente "funcional", e intencionadamente sin una explotación de recursos particularmente llamativos, que habrían de reservarse, por parte del compositor, para otras solemnidades del calendario litúrgico, de mayor significación).

Constituye una novedad característica del estilo clásico, puesto que aparece con función de acompañamiento de un tema y supone, por tanto, el abandono de la textura contrapuntística en favor de la melodía acompañada, construyéndose a partir de la concepción armónica, dado que en puridad, consiste en un acorde desarrollado. Como se anotó en el apartado del estilo compositivo, representa el empleo de un sistema "cercano" al tonal, la funcionalidad estructural, el acorde desplegado como sostén armónico, la jerarquización de las voces, y la melodía estructurada.

Veamos algunos ejemplos de acompañamiento a basa de acordes desplegados en los compositores y organistas extranjeros coetáneos:

-D’AQUIN, Louis Claude: Noël (cc.74-76): acompañamiento a base de acordes desplegados.

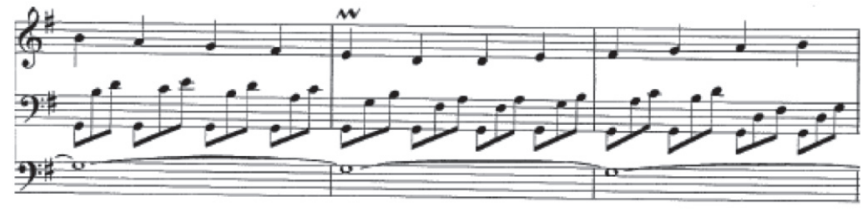

-D’AQUIN, Louis Claude: Noël (cc.127-128): variante del ejemplo anterior.

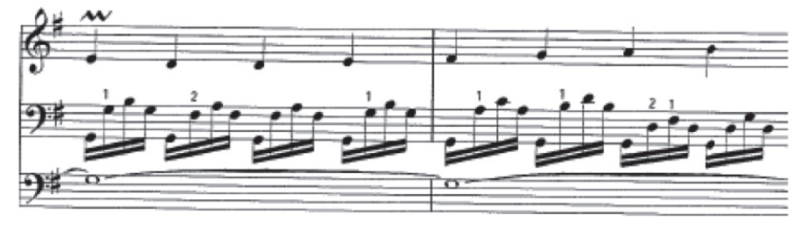


-LASCEUX, Guillaume: Simphonie Concertante (cc.1-3): melodía con acompañamiento de bajo de Alberti:

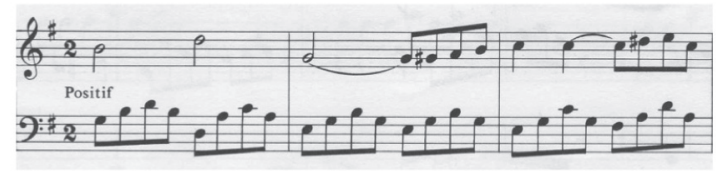

-LASCEUX, Guillaume: Simphonie Concertante (cc.10-12): textura clásica galante con melodía y acompañamiento de Alberti desarrollado en varios compases por terceras y segundas:

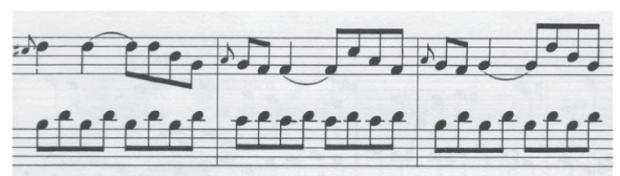

-SCHNEIDER, Johann Julius: Präludium (cc.3-4): textura con bajo Alberti asignado a la mano derecha. [El tercer sistema corresponde al pedalier].

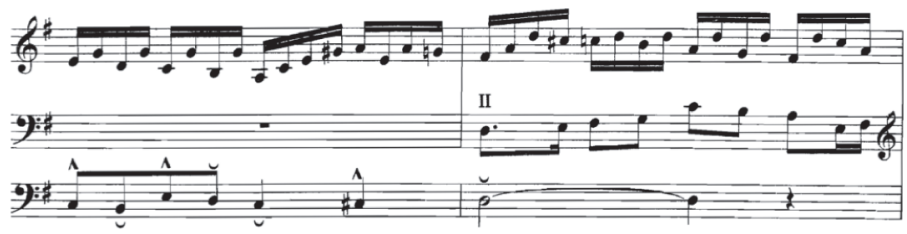

-KREBS, Johann Ludwig: Trio II (cc.27-31): escritura galante a base de acordes desplegados o bajos de Alberti.

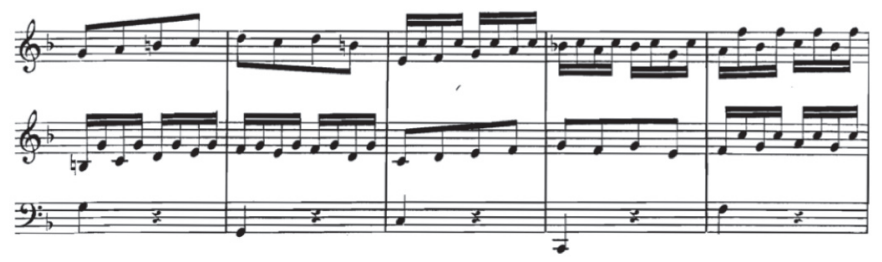


-GALUPPI, Baldassare: Sonata (cc.43-45, y 63-65): textura a base de acordes desplegados.

a)

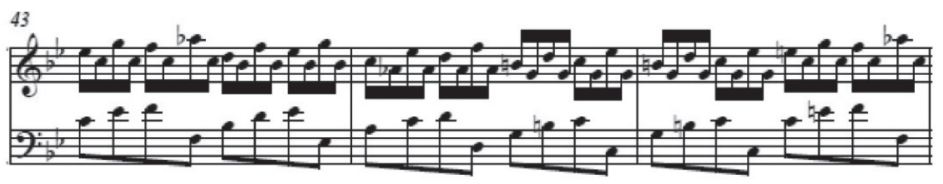

b)

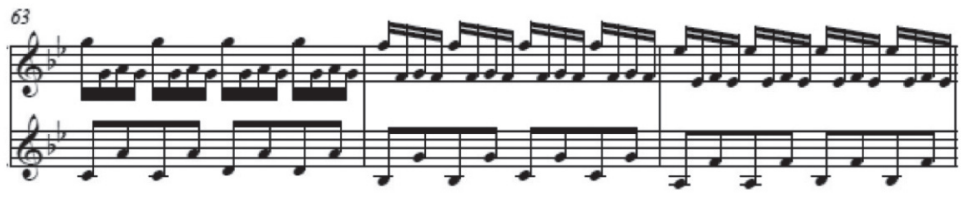

-ALBRECHTSBERGER, Johann Georg: Praeludien. I (cc.3-8): textura de acordes desplegados o arpegios, en la mano derecha:

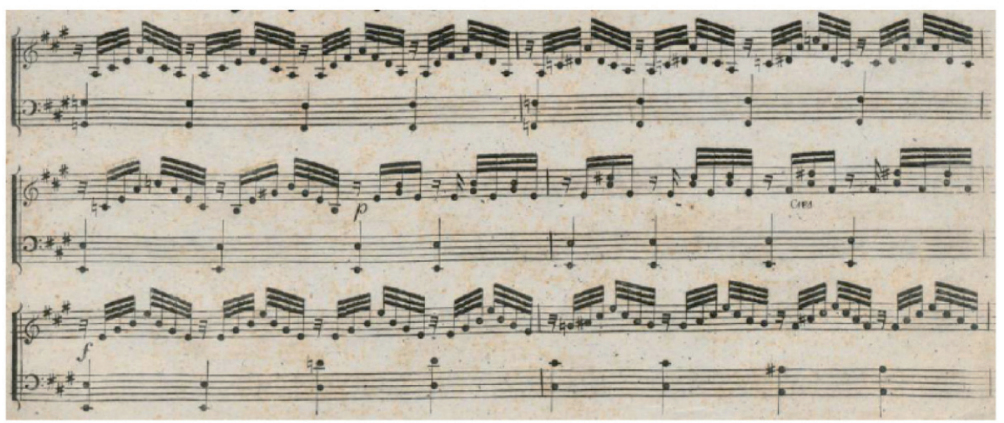

Estilo Cláusulas o Coral. Juan MORENO Y POLO. (Salmodia de misas para días clásicos. Verso $7^{\circ}$ del Primer Tono):

El estilo a base de un tratamiento simétrico o isorrítmico de las voces, la figuración en mínima y semínima, el reposo constante en cláusula, así como el movimiento por grados conjuntos de las voces individuales, y el final en "picardie", constituye otro de los procedimientos compositivos tradicionales del versillo orgánico. 

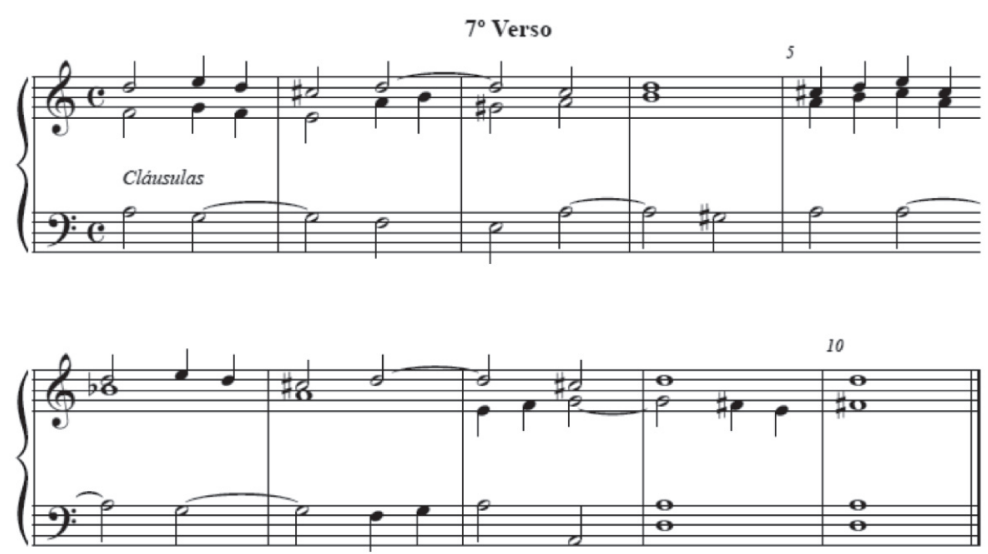

Desde el punto de vista de la estructura podemos diferenciar dos partes:

-c.1 hasta el c. 4: donde se anota una cláusula bien de II grado (Mi) eludiendo la fundamental y con $7^{\mathrm{a}}$, bien de IV grado (Sol) alterado (con sostenido), que resuelve en el V grado (La).

-c.5 hasta el final (c.10), con la cláusula preceptiva sobre Re.

A diferencia de todos los versos anteriores (que no se anotan en el presente estudio), la textura presenta un tipo de contrapunto que sugiere un tratamiento escolástico o riguroso más cuidado, a modo de Coral, esto es: textura a base de mínimas y semínimas, ritmo armónico de mínima o semibreve y cláusulas de reposo entre las partes. La indicación, al inicio de la pieza, de "Cláusulas" en origen hacía referencia a un tipo de pieza, que se construye añadiendo una voz por intervalo de $4^{\mathrm{a}}, 5^{\mathrm{a}}$ y $8^{\mathrm{a}}$ a la voz del Tenor, y que en el verso presente se entiende más bien como una sucesión de reposos o cláusulas propios del tono de Re dórico, particularmente apta para ofrecer un sustento de apoyo a la liturgia, un ambiente propicio para los versículos de la salmodia.

Ejemplo: (cc.1-2, textura de coral)

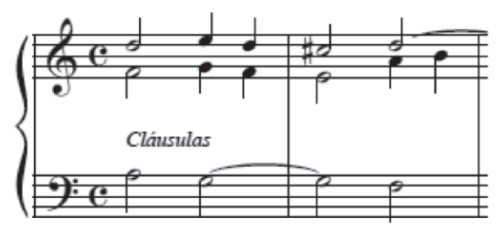

Mientras la voz inferior (mano izquierda) realiza un bajo sobre cuatro notas (propias de la escala del modo: La-Re), la mano derecha procede reiterando y afianzando el I grado (Re) en figuración de mínima o semínima y con notas de paso; la línea melódica más aguda (voz de Tiple) se mueve en el ámbito de las 
notas: Mi-Re-Do\#-Do); por su parte, la línea melódica que se sitúa por debajo de ésta (voz de Alto), se mueve en un ámbito melódico de $6^{\mathrm{a}}$, Mi-Do, y constituye el más extenso de las tres voces.

Tratamiento de la disonancia:

Choques directos:

-c.8, tiempo $3^{\circ}$ : La-Sol, donde el Sol resuelve en Fa\# (disonancia regular)

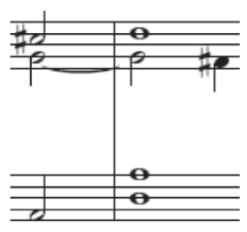

Choques indirectos:

-c.1, tiempo $4^{\circ}$ : Sol-Fa, donde el Fa resuelve en Mi (disonancia regular).

-c.3, tiempo $1^{\mathrm{o}}$ : Mi-Re, donde Re resuelve en Do (disonancia regular).

-c.4, tiempo $1^{\mathrm{o}}$ : La-Si, donde el La resuelve en Sol\#. (disonancia regular).

-c.5, tiempo $2^{\circ}: \mathrm{La}-\mathrm{Si}$, donde el Si resuelve en Do (disonancia regular).

-c.6, tiempo $1^{\mathrm{o}}$ : La-Si, donde el La resuelve en Sol (disonancia regular).

-c.7, tiempo $1^{\circ}$ : Sol-La, donde el Sol resuelve en Fa (disonancia regular).

-c.7, tiempo $4^{\circ}$ : Sol-La, donde el Sol resuelve en La (disonancia irregular).

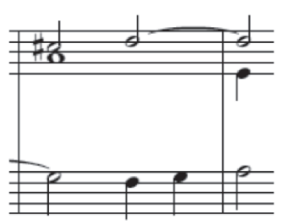

-c.9, tiempo 1\%: Sol-La, donde el Sol resuelve en Fa\# (disonancia regular). -c.9, tiempo $4^{\circ}$ : Re-Mi, donde el Mi resuelve en Fa\# (disonancia regular).

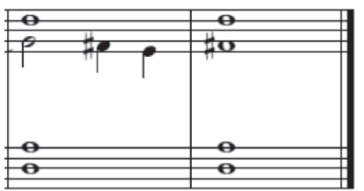


Veamos ahora algunos ejemplos de textura de Coral en algunos compositores-organistas extranjeros coetáneos:

-FISCHER, Michael Gotthard: Jesu Redemptor Omnium: hacia el final de la pieza, con escritura coral:

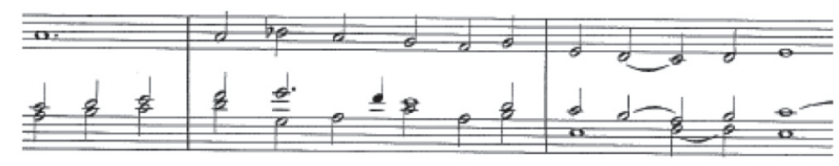

-KOP̌̌IVA, Karel Blažej: Fuga en La b Mayor (cc.24-26): textura coral durante toda su obra. El pedal es tratado de forma contrapuntística, como una voz más.

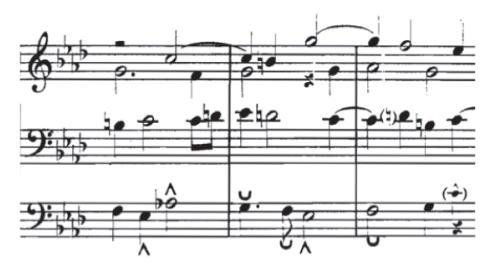

-KIRNBERGER, Johann Philipp: Chorale. Es ist das Heil uns Kommen her, cc.1-7

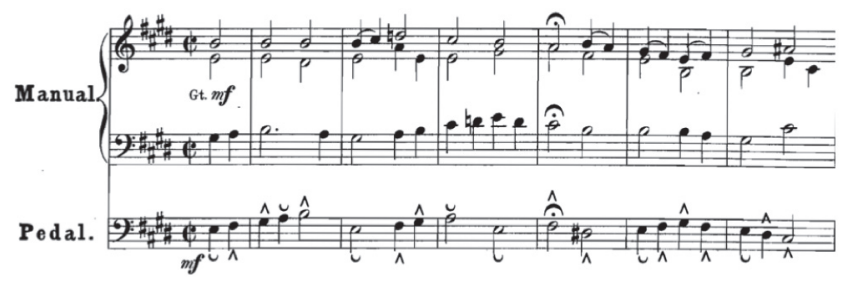

Estilo Improvisado (con “Acordes de Telón”). Manuel CIURANA. (Salmodia de misas para días clásicos Verso $1^{\circ}$ del Primer Tono):

Desde el tiento renacentista, el estilo improvisado ha representado uno de los procedimientos asociados a la composición para órgano de ámbito hispánico. Aquí es evidente el carácter introductorio para el primer verso, cuya registración bien podría recomendar lengüetería (por su carácter estridente y de llamada de atención sobre el tono), con un estilo virtuosístico por medio de escalas, que recorren las notas del tono, la mano izquierda únicamente a modo de sostén armónico, y la simplicidad de la figuración. 
En el ejemplo siguiente, el estilo improvisado basado en el contraste de textura entre ambas manos; frente a la mano derecha virtuosística a base de escalas rápidas, la mano izquierda procede a modo de acordes que introducen las notas de la nueva escala. La voz principal suena sin acompañamiento en los pasajes de escalas, reclamando la atención auditiva en la pericia técnica del organista. La obra se inicia con el recurso típico de apertura de muchas óperas, los acordes de telón, procedimiento característico del estilo clásico, puesto que sirve para asentar la tonalidad, al tiempo que avisa del inicio de la obra (como en los teatros, con los toques de llamada típicos, en el momento justo antes de descorrer el telón).

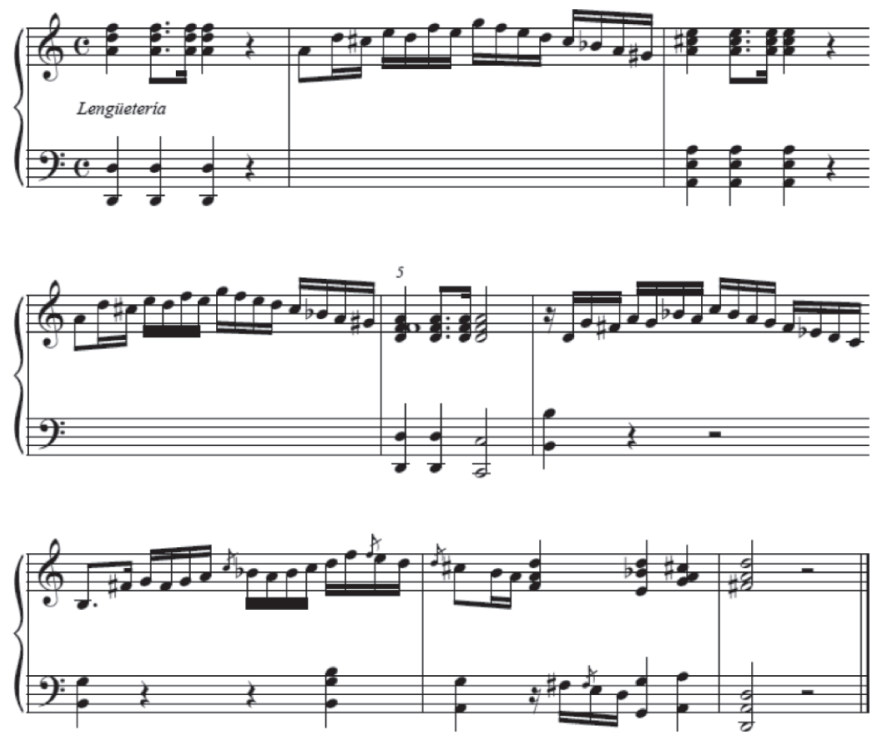

Este primer verso, se anota, como corresponde al primer tono, por natura (sin alteraciones propias en la armadura) y con finalis en Re.

Estructuralmente, este verso, únicamente de nueve compases, se organiza en dos secciones:

- Del c.1 al c.5: exposición, y repetición de los dos compases "modelo", hasta llegar a un "reposo" sobre el acorde triada del I grado².

2 Terminológicamente, para nuestro caso concreto español, todavía en esta época resulta complicado utilizar la nomenclatura tonal mayor-menor propia de la armonía funcional. En este sentido, trataré de evitar, en la medida de lo posible, la referencia a conceptos como por ejemplo "tónica", "dominante", subdominante", etc., si bien, para no haber de estar constantemente refiriéndome a "finalis"/unisonus, "repercursio"/diapente, "mediación", diatésaron, emplearé las expresiones "I grado", "II grado", "III grado", etc., sin que éstas impliquen "función" ni jerarquía alguna, sino simplemente orden en la escala o modo eclesiástico correspondiente. Al contrario, utilizaré cuando sea necesario el término "acorde", ya que la expresión del mismo aparece reflejada ya en la teoría musical de la época, a nivel europeo desde Jean Philippe Rameau, y dentro del ámbito hispánico ya al menos desde la edición del tratado de José de Torres. Si bien soy consciente de las discusiones a que esto puede dar lugar, es evidente que en las obras para teclado objeto de mi estudio aparecen ya claramente superposiciones de sonidos no sólo tríadas, sino incluso cuatríadas, lo que, en cierto modo, implica una tensión que precisa de una obligada resolución, si bien en ningún caso vamos a percibir un procedimiento compositivo dialéctico, como el que se refiere al ámbito centroeuropeo, tensional o conclusivo. Herencia seguramente 
- Del c.6 hasta el final: repetición del c. 2 y c.4 a la 5 a inferior; sigue otra parte libre (nueva, diferente), como preparación y resolución de la cláusula final V-I (finalizando con la preceptiva tercera de Picardie).

La textura se corresponde con la propia o habitual en pasajes imitativos, aunque incorporando algunos compases que recuerdan la técnica compositiva propia de las variaciones o diferencias de carácter improvisado (con glosa a partir del tono eclesiástico).

Ejemplo de los dos primeros compases, "modelo" rítmico-imitativo:

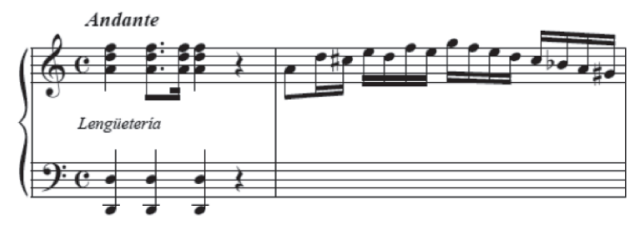

Escritura: la parte "improvisada" se encuentra siempre en la mano derecha, que alterna figuraciones rápidas con compases en acordes tríadas completos; mientras, la mano izquierda realiza unas octavas de apoyo y otros intervalos. Sólo en el penúltimo compás encontramos una pequeña muestra de lo que podría ser un "eco imitativo" en la mano izquierda consistente en tres semicorcheas.

Tratamiento de la disonancia: las partes libres de la mano derecha no llevan ningún tipo de acompañamiento, por lo que no originan disonancias. Las únicas disonancias directas se encuentran en el c.8, mano derecha, tercer tiempo (Mi-Re) y cuarto tiempo (Sol-La), originadas por los acordes cuatreadas que se forman en los respectivos tiempos. También aparecen tres disonancias indirectas en estos mismos compases, aunque muy breves, en valores de semicorchea. $Y$ un intervalo recurrente de $5^{\text {a }}$ aumentada (Sib-Fa\#) en el c.6 y c.7:
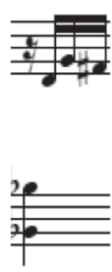
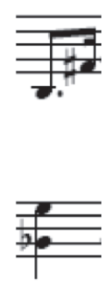

de la tradición modal española, la música que presento, a pesar de la posición de séptimas o cuatríadas que se puedan encontrar, no persigue necesariamente la creación de una tensión conclusiva precisada de resolución, sino que, más bien, como en el caso de la modalidad, su carácter puede ser puntualmente de reposo, e incluso, en algunas ocasiones, conclusivo pero dentro de un marco o entorno modal suspensivo. 
De estos parámetros se puede deducir que el carácter que se pretende dar a la pieza es una suerte de introito, introducción a cuánto va a venir a continuación, la obra se inicia con el recurso típico de apertura de muchas óperas (los acordes de telón o Akkorden der Vorhang öffnet), que asientan la tonalidad, al tiempo que avisan del inicio de la obra (como en los teatros, con los toques de llamada típicos, en el momento justo antes de descorrer el telón).

En cuanto a la ornamentación, no aparecen signos de articulación, ni dinámicas, aunque sí se utilizan acciacaturas (en los compases 2, 4, 7 y 8). Por lo tanto, de la carencia de matices y signos propios del fortepiano -en una escritura que podríamos calificar en tal sentido como plana-, así como de la concreción de registración, se trasluce un vocabulario específicamente para el órgano (y no intercambiable para otros posibles instrumentos de teclado -dado que tampoco parece estar pensado para un clave o un clavicordio-).

Estilo Dialogado. Manuel CIURANA. (Salmodia de misas para días clásicos Verso $2^{\circ}$ del Primer Tono):

El estilo dialogado representa una variante del estilo fugado, aunque sin las entradas características del estilo fugado, el verso se muevo contrapuntísticamente por medio del tratamiento individualizado de las voces, la polifonía sucesiva, no simultánea, el movimiento por grados conjuntos, y la cromatización pasajera. Los temas no constituyen carácter melódico, por la variación constante del mismo material, ya que representan más bien motivos desarrollados.
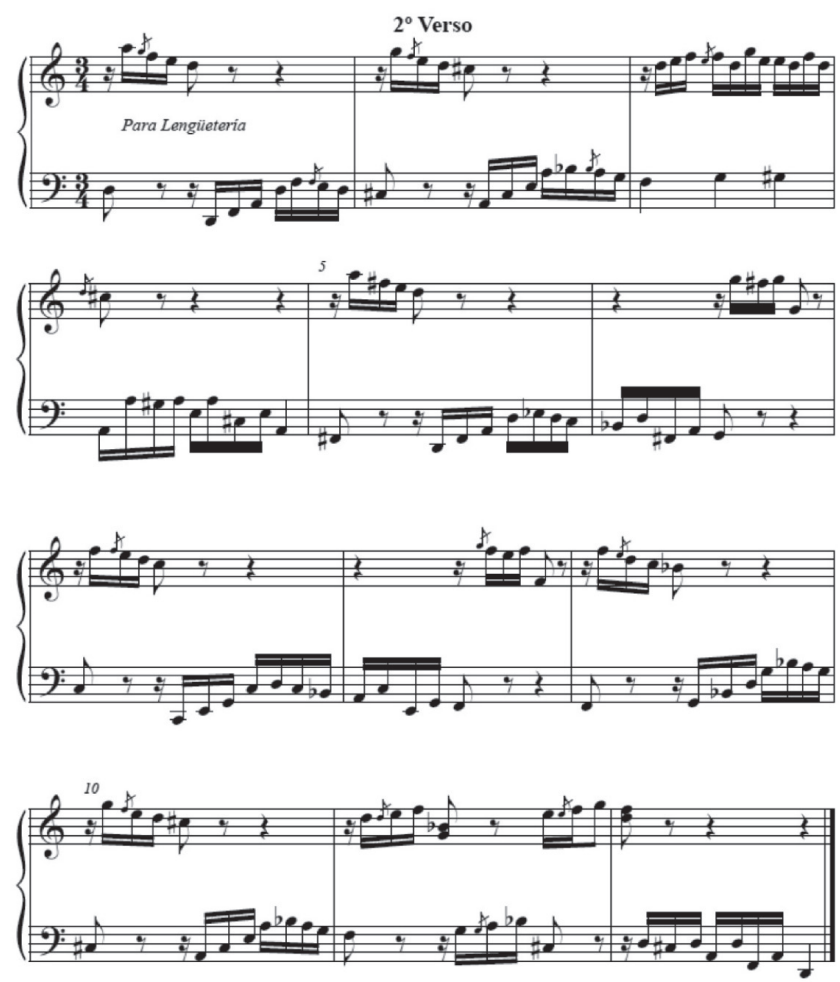
Este segundo verso, se anota, como corresponde también al primer tono, por natura (sin alteraciones propias en la armadura) y con finalis en Re.

Estructuralmente, este verso, de doce compases, se organiza en tres secciones:

- Del c.1 al c.4: exposición del compás modelo (c.1), repetición del mismo (c.2), y preparación de una cláusula en el $v$ grado del tono.

- Del c.5 al c.8: exposición del "modelo imitativo", ahora formado por dos compases y repetición del mismo.

- Del c.9 hasta el final: se recupera el modelo imitativo de un compás de la primera sección; luego, repetición del mismo; y preparación y resolución de la cláusula final, en el i grado de la tonalidad.

La textura es de tipo imitativo (contrapuntístico), con carácter de pregunta-respuesta, alternando en la ejecución ambas manos, pero en ningún caso con simultaneidad de voces, lo que aporta un cierto carácter juguetón a la pieza (avanzado para el entorno eclesiástico de la época en el sentido de que se aproxima a la variación moderna -y quasi romántica-, "scherzando"). En la escritura, utiliza sólo dos voces, que únicamente se encuentran al herir el segundo y tercer tiempos del c.3, y en el primer tiempo (fuerte) del c.4.

El primer compás servirá de modelo al c.2, 9 y 10.
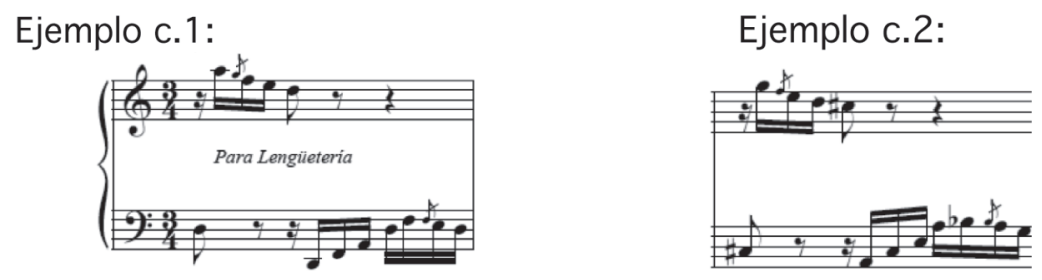

Los cc.5 y 6 forman otro modelo imitativo que se repetirá en los cc.7 y 8 .

Ejemplo cc.5-8:

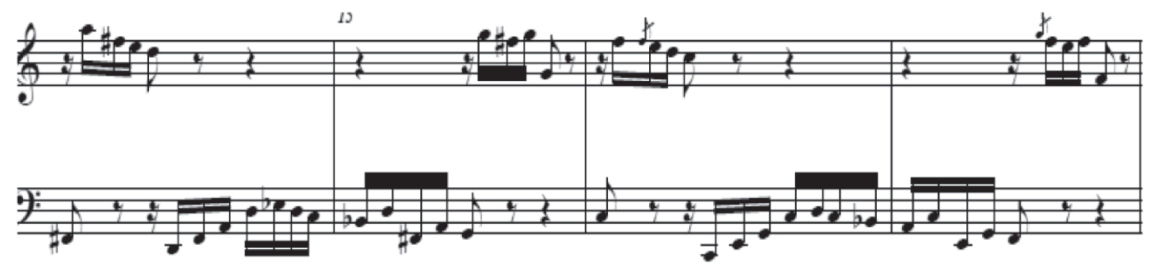


Esto denota la realización de un trabajo a partir de pequeñas células, que más tarde se irán aprovechando como material temático susceptible de ser reutilizado, ya sea mediante un procedimiento variado, ya de copia, ya de transporte a diferentes alturas, en diferentes planos físicos sonoros (manos), añadiéndole notas de paso, suprimiendo partes del modelo original, etc. Esta recurrencia y procedimiento compositivo de la variación constante del material temático, fundamentado en un pequeño motivo con carácter diferenciando (Satz), constituye una concepción de la música, que alejada del trabajo contrapuntístico de nota contra nota de la "prima prattica", será el germen constructivo de la forma musical desarrollada; es decir, a partir de ahora, empieza a atisbarse un paso desde la mera yuxtaposición de materiales, generalmente breves (pocos compases), hacia una organización de los materiales mucho más estructurada, que devendrá, a partir de ahí, a organizar arquitectónicamente toda la composición, generada por motivos muy simples, a los que ahora se dotará de intervenciones cíclicas.

Tratamiento de la disonancia: hay una disonancia indirecta en el tercer tiempo del c.3: Sol\#-Fa, que, puesto que resuelve por salto a la nota Re, podríamos considerar como un acorde de séptima disminuida desarrollado.

Ejemplo c.3:

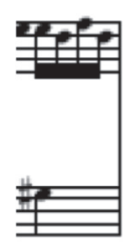

Indicación de compás: cambia a 3/4, con lo que obtiene un interesante cambio de acentuación respecto al discurso general de la ejecución.

La indicación específica para órgano recomienda "Para Lengüetería", y tampoco hay signos de articulación, ni dinámicas, lo que mantiene el ambiente general de la obra, aportando la continuidad necesaria, al tiempo que en cuestión de ornamentación, sigue utilizando las acciacaturas (que contribuyen a ese carácter "scherzando" ya comentado, ofreciendo un valor añadido de mayor dificultad técnica o de ejecución).

Como se indicó, constituye una variante del estilo fugado, el verso se muevo contrapuntísticamente por medio del tratamiento individualizado de las voces y la polifonía sucesiva. Veamos algunos ejemplos de contrapunto dialéctico en algunos compositores y organistas extranjeros coetáneos:

-GALUPPI, Baldassare: Sonata per flauto (cc.7-10): pregunta-respuesta.

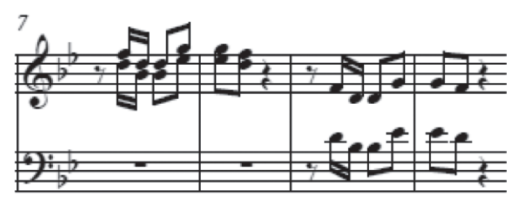


-LASCEUX, Guillaume: Trois Noël Variés pour l'Orgue ou le Clavecin. On s'envont des gais Brewers. $8^{\mathrm{e}}$ Variation (cc.1-3): procedimiento en pregunta-respuesta.

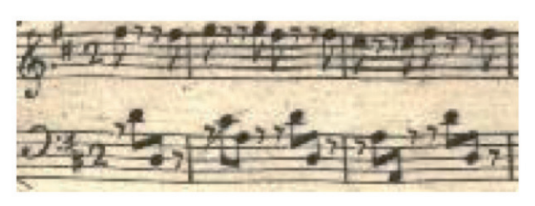

-LONG, Samuel: Lesson III, Allegro (cc.8-9): pregunta-respuesta.

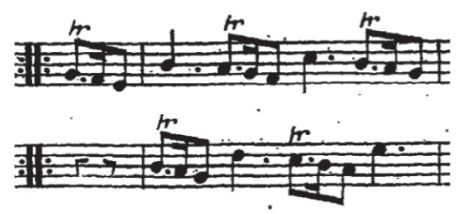

\section{LA MODALIDAD ${ }^{3}$}

Como se indicó en los apartados precedentes, la forma musical Salmódica constituye una organización sistemática por los ocho tonos o modos clásicos, por lo que ofrece la oportunidad de conocer cuál era el modelo y procedimiento estándar, de lo que se entendía en la España o Valencia del siglo XVIII por cada uno de los tonos eclesiásticos; la costumbre de tratarlos o anotarlos por natura, transportados, o de posibles interpretaciones extrañas a la tradición y norma. Este apartado ha de entenderse, por tanto, como significativo de los procedimientos habituales en el tratamiento de la modalidad por parte de dos organistas clásicos "valencianos" y no de manera estadística o de recopilación sistemática de ejemplos musicales al respecto. Se procede a modo de una "foto fija" sobre dos autores clásicos (Juan MORENO Y POLO y Manuel CIURANA), por lo que ha de interpretarse con la flexibilidad propia que resulta del mismo cotejo único entre ambos autores, y del hecho de que los resultados de la comparativa no resultan del todo idénticos.

Lejos de querer mostrar la estadística del procedimiento modal de los organistas valencianos durante el periodo ilustrado, se ofrece una pequeña muestra significativa que resulta de la comparativa entre dos obras inéditas, como aproximación o modelo para ulteriores procedimientos de estudio sobre la modali-

3 Como se puede comprobar, se editan y estudian dos salmodias para misas de Juan Moreno y Polo, que aquí diferenciaré como "Juego 1 " " y "Juego 2 ", respectivamente. En la presente comparativa, en el caso de que no se haga mención expresa a las dos por separado, entiéndase que ambas coinciden en lo relativo a su manera de concebir la tonalidad correspondiente 
dad orgánica. Nótese la gran cantidad de semejanzas entre ambos autores así como unas pequeñas pero significativas diferencias.

TONO $1^{\circ}$ : Juan MORENO Y POLO: Re, por natura; Manuel CIURANA: Re, por natura.

Juan Moreno y Polo
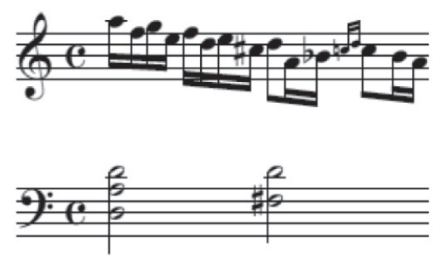

Manuel Ciurana

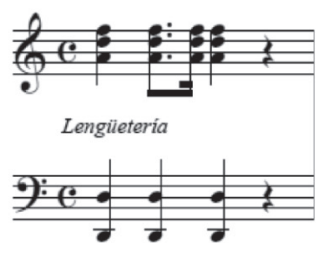

TONO $2^{\circ}$ : Juan MORENO Y POLO: Mi, transportado, con 1 sostenido; Manuel CIURANA: Mi, transportado, con 1 sostenido.

Juan Moreno y Polo

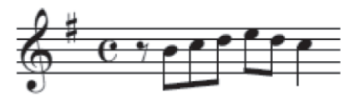

$9: \frac{700}{100}$
Manuel Ciurana
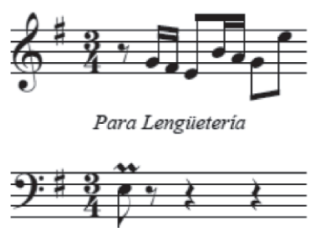

TONO 3: Juan MORENO Y POLO: Re, transportado, con 2 bemoles; Manuel CIURANA: Re, transportado, con 2 bemoles.

$$
\text { Juan Moreno y Polo }
$$
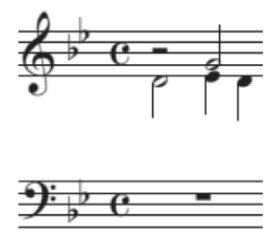

Manuel Ciurana

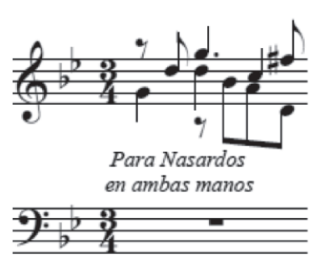


TONO $4^{o}$ : Juan MORENO Y POLO: Mi, por natura; Manuel CIURANA: Mi, por natura.
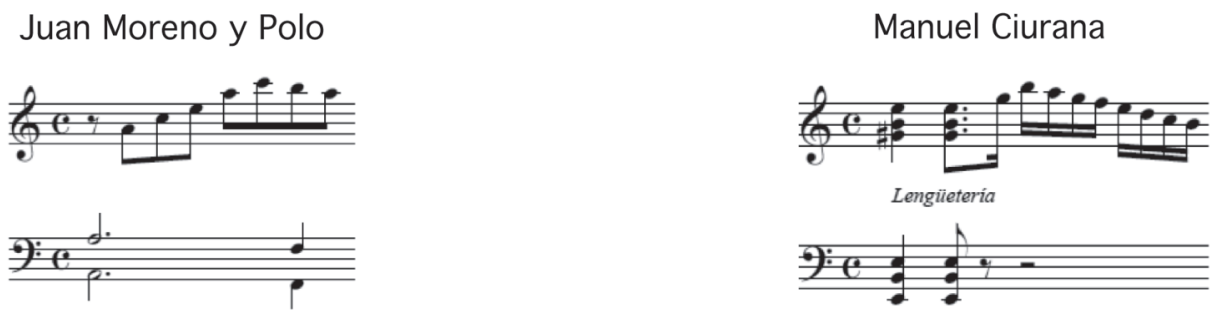

TONO 5: Juan MORENO Y POLO: Do, por natura; Manuel CIURANA: Do, por natura.
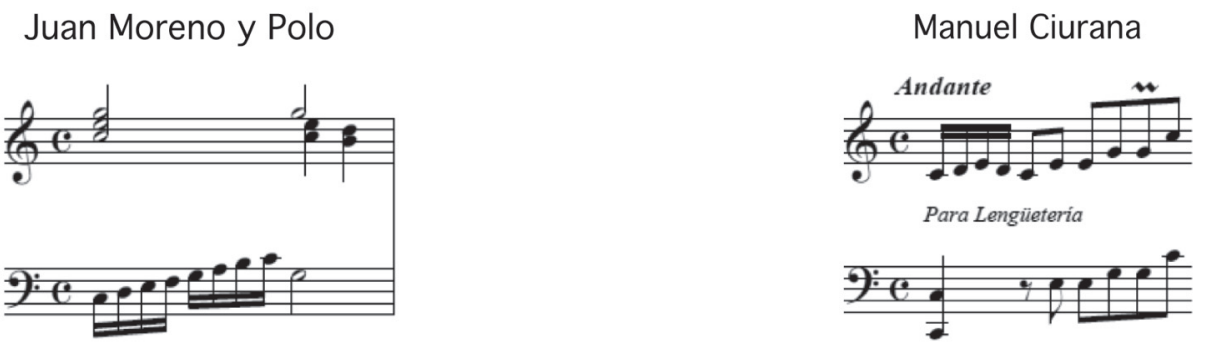

TONO $6^{\circ}$ : Juan MORENO Y POLO: Fa, transportado, con 1 bemol; Manuel CIURANA: Fa, transportado, con 1 bemol.
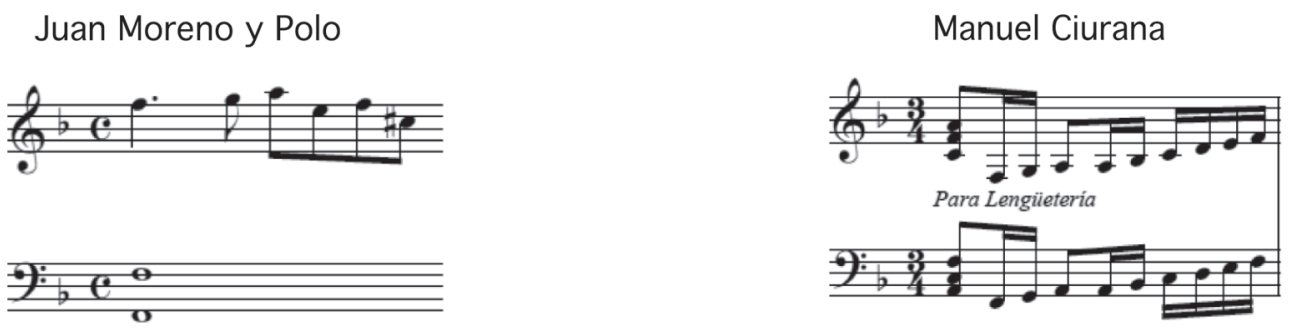

TONO $7^{\circ}$ : Juan MORENO Y POLO: [Salmodia $1^{\text {a }}\left(\right.$ Juego $^{\circ}$ ):] tratamiento irregular: Sol mixolidio, transportado [semejante al cronológicamente posterior Sol menor], anotado, bien con 1 bemol, bien con 2 bemoles en su armadura (y con frecuentes cláusulas sobre su v grado, Re). [Salmodia $2^{\mathrm{a}}\left(\mathrm{Juego} 2^{\circ}\right.$ ):] No se ha compuesto; Manuel CIURANA: No se ha compuesto. 


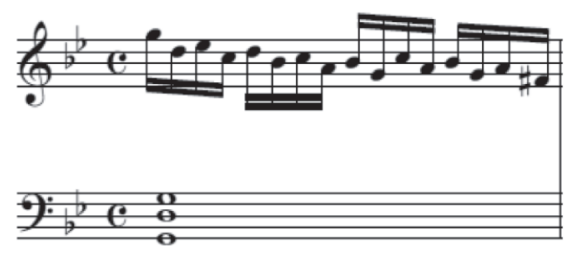

TONO $8^{o}$ : Juan MORENO Y POLO: [Salmodia $1^{\text {a }}$ (Juego $1^{\circ}$ ):] tratamiento irregular: Sol hipomixolidio, transportado [semejante al cronológicamente posterior Sol Mayor], anotado, con 1 sostenido en la armadura (y con frecuentes cláusulas sobre su v grado, Re). [Salmodia $2^{\mathrm{a}}$ (Juego $2^{\circ}$ ):] ( $8^{\circ}$ Tono o "Quinto, punto alto") Re, transportado, con 2 sostenidos; Manuel CIURANA: Re, transportado, con 2 sostenidos.
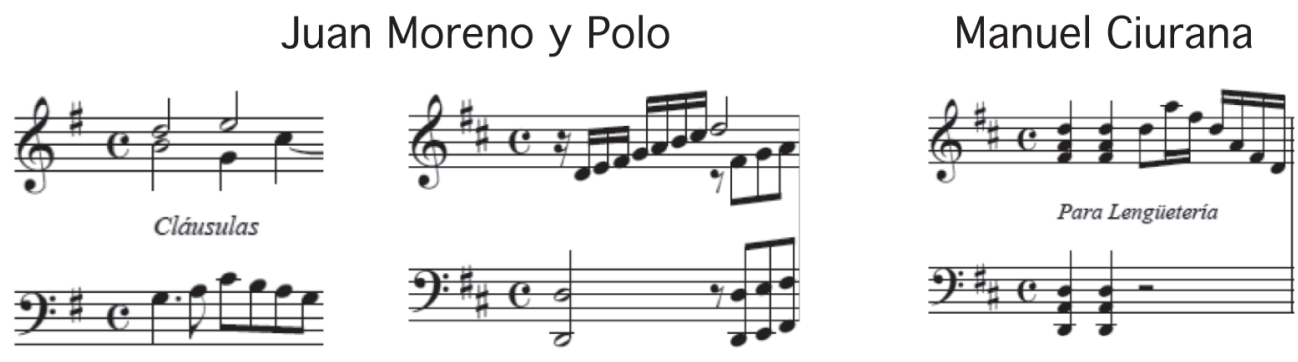

Se trata, tanto el caso de la salmodia de misas para días clásicos de Manuel Ciurana, como en el de los dos juegos de salmodia para misas de Juan Moreno y Polo, de "ciclos" completo de Versos para órgano, ordenados modalmente.

El esquema tonal que siguen ambos autores es casi el mismo, si se exceptúan los tonos que no se han compuesto: falta el Tono $3^{\circ}$ en la Salmodia $1^{\mathrm{a}}\left(\right.$ Juego $1^{\circ}$ ) y el Tono $7^{\circ}$ en la Salmodia $2^{\mathrm{a}}\left(\operatorname{Juego} 2^{\circ}\right.$ ), ambos de Juan Moreno y Polo, así como también, en este último caso (Tono $7^{\circ}$ ), en la Salmodia de Manuel Ciurana.

De este modo, ninguno de los tres ciclos mencionados cuenta con los 64 versos (ocho versos, por los ocho tonos), sino que, todos ellos, carecen de algún tono, o incluso dentro de algún tono, no llegan a componer ocho versos, sino alguno menos. En cualquier caso, se trata de excepciones, probablemente debidas a que se trata de tonos que habían perdido uso y vigencia en la época a favor de otros más trabajados, acaso por sus mayores posibilidades de ensamblarse con el sistema tonal mayor-menor (lo que es particularmente apreciable en el caso del Tercer Tono y en cierta menor medida, en el caso del Séptimo 
Tono). [Nótese también como al Tono $8^{\circ}$ se le llama ya "Tono $5^{\circ}$ punto alto", que se identifica plena y claramente con Re Mayor, aunque se evita dicha terminología seguramente para amoldarse al contexto eclesiástico modal propio de los versos para acompañar la salmodia].

En este sentido, y a pesar de su posible descontextualización eclesiástica, estos ocho tonos van a sonar ya, para un oyente actual (sin entrar aquí en pormenores o mayores disquisiciones conceptuales o teóricas) de la manera siguiente:

Tono $1^{\circ}=$ Re dórico $\simeq$ Re menor ( in bemol en la armadura, aunque el vi grado se altere accidentalmente con relativa frecuencia)

Tono $2^{\circ}=\mathrm{Mi}$ (hipo)dórico transportado $\simeq$ Mi menor (con un sostenido en la armadura)

Tono $3^{\circ}=$ Re frigio transportado

Tono $4^{\circ}=\mathrm{Mi}$ (hipo)frigio

Tono $5^{\circ}=$ Do lidio $=\left[\right.$ Tono $11^{\circ}=$ Do jonio $] \simeq$ Do Mayor (por natura)

Tono $6^{\circ}=\mathrm{Fa}$ (hipo)lidio transportado $=\left[\right.$ Tono $11^{\circ}$ transportado $=\mathrm{Fa}$ jonio $] \simeq \mathrm{Fa}$ Mayor

Tono $7^{\circ}=$ Sol mixolidio $=$ Sol menor $($ con un solo bemol en la armadura teniendo el segundo bemol alterado accidentalmente)-Re menor (con un bemol en la armadura)

Tono $8^{\circ}=\operatorname{Re}($ hipo $)$ mixolidio transportado $\simeq$ Re Mayor

En el caso concreto de las dos salmodias de Juan Moreno y Polo, analizado ya el modo de entender cada uno de los tonos previamente, para el caso de Manuel Ciurana, y sus equivalencias y divergencias respecto al organista de la catedral de Tortosa, únicamente resta explicar cómo este último ha concebido el Séptimo Tono, dado que dicha tonalidad no aparecía en el caso de Ciurana.

Juan Moreno y Polo anota este Séptimo Tono de la manera siguiente:

-Primer verso con dos bemoles en la armadura comienzo en Sol y final en Re (una suerte de Sol menor, que clausula sobre el v grado);

-Segundo verso con un bemol en la armadura y Sol al comienzo y final en Re (en un caso más cercano al tradicional Sol mixolidio - por natura - , que, algo evolucionado ya hacia el sistema tonal mayor/ menor, ha adoptado ya un primer bemol en la armadura, pero todavía no ha asumido ese segundo bemol que sería más propio del "tonal” Sol menor).

-Tercer, cuarto y sexto versos, con un bemol en la armadura (aunque se altera accidentalmente el Mi bemol durante todo el versillo), comienzo en Sol y final en Re (nuevamente, en una escala próxima a Sol menor, con su segunda alteración anotada no en la armadura, sino accidentalmente, y clausulando sobre su V grado).

-Quinto verso, con un bemol en la armadura (alteración con Mi bemol durante toda la pieza) comienzo en Re y final en Re (como corresponde a la parte estructuralmente álgida - poco después de su centro - de los siete versos en este mismo tono, manteniendo a lo largo de todo el versillo el $\mathrm{V}$ grado de ese peculiar Sol menor con un único bemol anotado en la armadura y que únicamente altera el segundo bemol sobre el Mi accidentalmente).

-Séptimo verso un bemol armadura comienzo en Sol y final en Sol (alterando el Mi bemol, de manera que se regresa, desde el anterior $\mathrm{V}$ grado de la escala - aparecido desde la finalización del primer 
versillo y mantenido con posterioridad - hasta su I grado nuevamente, en un peculiar Sol menor que solamente anota accidentalmente su segunda alteración), para acabar ahí toda la serie de este séptimo tono (sin incorporar un $8^{\circ}$ versillo al juego). De esta manera, Juan Moreno y Polo construye aquí un tono intencionadamente "defectivo", por faltarle un versillo, así como por no anotar sobre la armadura algunas alteraciones que hubieran sido de precepto en un contexto tonal mayor/menor, de manera que el compositor se atiene, así, por un lado, a la tradición eclesiástico-modal para la que han sido concebidas todas estas pequeñas piezas, con una intencionalidad plenamente funcional, litúrgica, etc., al tiempo que demuestra, por otro lado, su clara vinculación a un nuevo ambiente (tonal mayor/menor) que inundaba ya, no sólo los templos - y desde hacía largo tiempo-, de forma que el autor patentiza a la vez, más allá de convencionalismos y estereotipos formales en este tipo de composiciones "modélicas", un cierto espíritu "moderno", o "a la moda".

En los autores autóctonos, los modos, se anotan con forma diatónica, pero se concibe ya de una manera cercana a lo "tonal", por ejemplo con el modo Protus entendido como cercano a Re menor, con el Si bemol alterado sistemáticamente de manera accidental, con el Do sostenido (entendido ya como un VII grado con una nueva función de "sensible"), y con otras alteraciones accidentales, propias ya de Re menor. Frente a estos rasgos de modernidad de los autores españoles, compárese con los siguientes ejemplos ya plenamente tonales de los autores foráneos; como en el caso de Josef Seger, con una armadura con varias alteraciones.

Veamos algunos ejemplos del tratamiento de la tonalidad en los compositores y organistas extranjeros coetáneos

-SEGER, Josef: Fugue en Fa mineur (cc. 1-3): gran número de alteraciones en la armadura frente a las composiciones españolas anotadas según la modalidad antigua. Repárese asimismo en el trabajo del pedalier, que constituye una parte más del contrapunto frente a los sencillos - casi rudimentarios - contras o pisas de la escritura española orgánica.

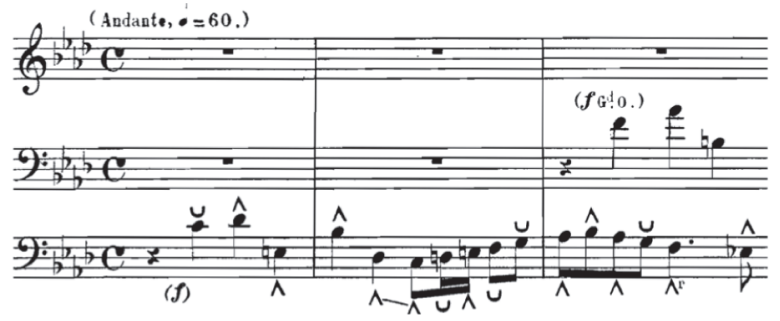


-SCHNEIDER, Johann Julius: Präludium (cc.32-34): menor trabajo del pedal, entendido para fijar las funciones tonales propias del Clasicismo, y textura acórdica (desplegada) asignada a la mano derecha, propia del estilo galante:

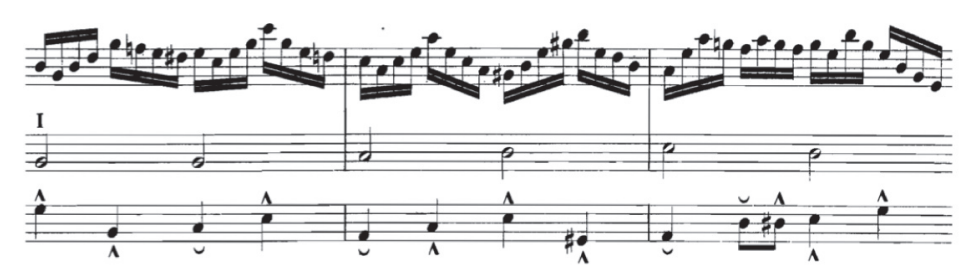

-KOP̌̌IVA, Karel Blažej: Fuga en La bemol Mayor (cc.1-5): alteraciones en la armadura propias específicamente de la tonalidad mayor:

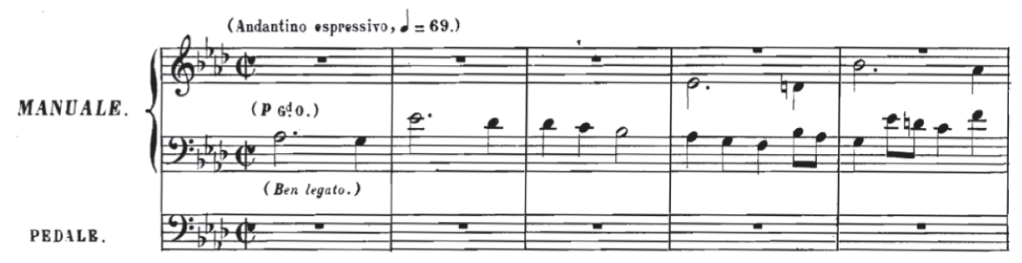

-FISCHER, Michael Gotthard: Jerusalem Plantabis (cc.1-3): pasaje con un tratamiento de glosa, frente a la escritura acórdica, y alteraciones accidentales sobre el Si bemol:

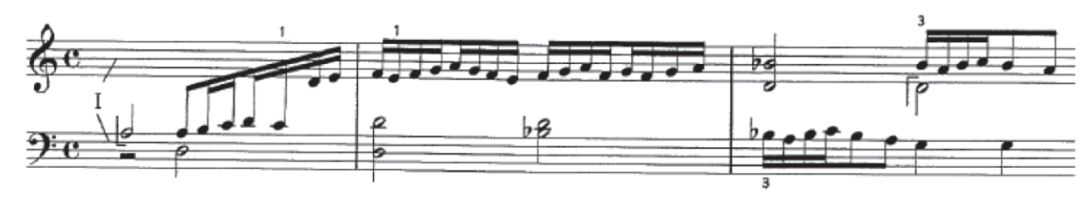

-FISCHER, Michael Gotthard: Jerusalem Plantabis (cc.5-6): alteraciones del modo (nota Do\#):

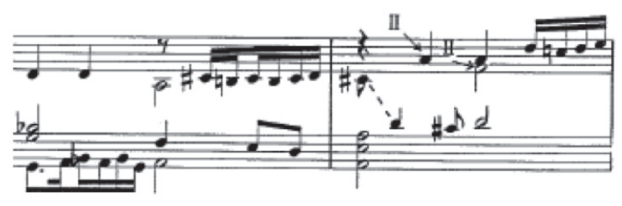


-FISCHER, Michael Gotthard: Jerusalem Plantabis (cc.10-11): en modo Protus; alteración de la nota Sol\#:

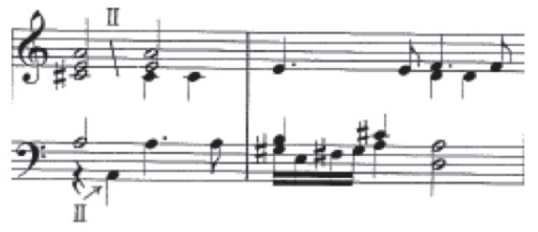

-FISCHER, Michael Gotthard: Jerusalem Plantabis (cc.22-23): alteración del Sol\#:

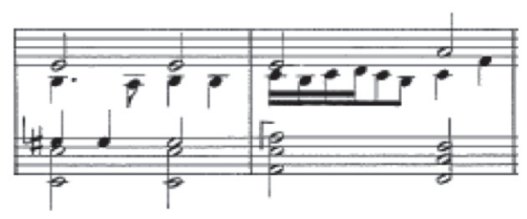

\section{CONCLUSIONES}

Como se ha podido constatar en el presente estudio analítico comparado, los autores y organistas objeto de estudio muestran un tratamiento compositivo que en buena medida procede conforme al estilo organístico del contexto europeo coetáneo, tanto en la preferencia por el tratamiento contrapuntístico, el empleo del tradicional estilo Cláusulas o Coral, como por la presencia de parámetros propios del nuevo contexto histórico ilustrado; empleo del bajo de Alberti, la melodía acompañada o el sistema tonal o híbrido tonal-modal.

Son de remarcar, en cambio, ciertos distanciamientos en lo que respecta a algunos aspectos del contexto europeo, con mayor "modernidad" en los compositores foráneos, particularmente en el tratamiento que de la armonía tonal, el tratamiento fugado de mayor complejidad textural y la ausencia, en el contexto europeo, del tradicional estilo improvisado de ámbito hispánico. Los autores autóctonos objeto de estudio, muestran en cambio, un estilo propio de la tradición organística hispánica, como son los breves "pasos fugados" que, a dos o tres voces, proceden a modo de entradas canónicas, y que, con el estilo improvisado y de Cláusulas, enlazan plenamente con el Renacimiento orgánico hispánico.

La combinación o amalgama de texturas en Juan Moreno (que aúna versos de textura melódica con pasos fugados, estilo coral, o improvisado), constituyen elementos de modernidad presentes también en los autores cotejados del contexto europeo, como el italiano Galuppi o el francés Lasceux (con una escritura propia del Clasicismo imperante, a base de melodía y bajo de Alberti), o incluso el alemán Kirnberger, con una escritura Coral típicamente asociada al entorno religioso Reformista. 
En el apartado de giros o procedimientos propios de la tradición musical y organística hispánica, se puede apreciar por parte de los autores objeto de estudio, una mayor tendencia al diatonismo que en el contexto europeo; una menor proliferación de alteraciones accidentales y también en la armadura, y por tanto una semejanza mayor con la tradición modal, que junto con los recursos más modernos, podríamos cifrar como sistema de tipo híbrido modal-tonal, diferenciado del contexto europeo general, ya plenamente tonal.

Por último, el empleo y explotación al máximo de los recursos "de efecto" que estaban al alcance de los músicos españoles y levantinos, supone, por un lado, una especificidad de la música orgánica española, pero, al mismo tiempo en esta época, ciertas aproximaciones, de uno y otro lado, respecto al diferente panorama europeo. Así, los compositores levantinos trabajan para unos instrumentos a su alcance generalmente carentes de pedalier (o apenas dotados de una octava de pisas o contras), frente a lo que sucediera al norte de los Pirineos, aunque a menudo equipados de registros partidos (que permitían mayores posibilidades combinatorias en cuanto a efectos y sonoridades).

$\mathrm{Si}$, normalmente, los órganos españoles no cuentan a menudo con unos fondos y principales -o "llenos" en español- tan poderosos como los de los instrumentos centroeuropeos (siendo el aparato fónico o "los pulmones" de los órganos españoles, a menudo, más dulces y de menor potencia, en virtud también de una menor presión a la que se somete su columna de aire), en contraposición, y a su favor, están dotados (y muy especialmente en el área catalano-levantina) de otros artificios, tales como la adición al órgano mayor de una cadereta u órgano de espalda, que les permite distintos efectos de estereofonía.

Estas peculiaridades (teclados en ocasiones partidos, registros partidos, una única octava de contras, unos principales menos agresivos que obligan a emplear registraciones imaginativas para obtener sonoridades grandilocuentes y masivas, añadidos como el órgano de cadereta y registros accesorios de carácter popular y juguetón que entonces se pusieron de moda -pajaritos, timbal o tambor, campanillas...-), ofrecen al organista hispánico (incluyendo aquí el área latinoamericana) la posibilidad de una ejecución particularmente individualizada, en la que el buen conocimiento del instrumento que se maneja, así como de sus posibilidades, e incluso la propia formación musical y experiencia concertística del ejecutante, y su creatividad personal, confieren a la puesta en práctica de la música española para órgano de la época, a partir de su misma escritura, un carácter paradójicamente no-escrito, sino "del momento" o improvisatorio.

En todo caso, puede apreciarse un tipo de escritura musical, en el ámbito local hispano, más bien tendente a la arquitectura formal breve y de corto minutaje, siempre muy compartimentada en composiciones que, en su conjunto, pueden llegar a ser globalmente extensas (juegos de versos por los ocho tonos, los cuales se conciben no para ser utilizados de corrido, sino independientemente -apenas un tono-), y siempre organizadas a partir de pequeñas células -brevísimas, casi rudimentarias en su concepción-, yuxtapuestas (los tonos, y dentro de ellos, cada uno de sus versos), como corresponde en general a las composiciones de carácter hímnico, y como sucede también en el caso del Coral germánico, o de los anthems británicos. 


\section{BIBLIOGRAFÍA}

EZQUERRO ESTEBAN, Antonio, ed.: Antonio Lozano: La música popular, religiosa y dramática en Zaragoza, desde el siglo XVI hasta nuestros días. (Zaragoza, Julián Sanz y Navarro, 1895). $3^{\mathrm{a}}$ edn., Zaragoza, Ayuntamiento-Diputación-Gobierno de Aragón, 1994.

—, La música vocal en Aragón en el segundo tercio del siglo XVII. (Tipologías, técnicas de composición, estilo y relación música-texto en las composiciones de las catedrales de Zaragoza). Tesis doctoral, 5 vols., Universitat Autònoma de Barcelona, 1997.

_, "Nuevos datos para el estudio de los músicos Nebra en Aragón”, en Anuario Musical, 57 (2002), pp.113-156.

-, Música instrumental en las catedrales españolas en la época ilustrada (conciertos, versos y sonatas, para chirimía, oboe, flauta y bajón - con violines y/u órgano-, de La Seo y El Pilar de Zaragoza). Barcelona, CSIC, col. "Monumentos de la Música Española, LXIX”, 2004.

GIMENO ESTORNELL, Vicent: L'Església Parroquial Sant Jaume Apòstol de Vila-Real. 225 Anys de la seua Història: 1779-2004. Villarreal, Impremta Llorens, 2006.

GONZÁlEZ VALlE, José V.: Organistas de las catedrales de Zaragoza. Madrid, Real Musical, "Serie de Música Histórica Aragonesa, fascículo I”, 1978, prólogo.

- , "Fondos musicales de D. Scarlatti conservados en el Archivo de Música del Pilar de Zaragoza", en Anuario Musical, 45 (1990), pp.103-116.

—, Ramón Ferreñac (1763-1832): Sonata para órgano a cuatro manos. Zaragoza, IFC, 1995.

—, [Francisco Javier García Fajer "el Españoleto":] Siete Palabras de Cristo en la Cruz. Barcelona, CSIC, col. "Monumentos de la Música Española, LXI”, 2000, pp. 17-72.

KASTNER, Macario Santiago: Contribución al estudio de la música española y portuguesa. Lisboa, Ática, 1941.

LORENTE, Andrés: El Por qué de la Música. Alcalá de Henares, Nicolás de Xamares, 1672 [edn. facsímil (GONZÁLEZ VALLE, José Vicente, ed.), Barcelona, CSIC, col. “Textos Universitarios, 38”, 2002], pp.618 (p.568 del original) y 674 (p.624 del original), respectivamente.

MARTÍN MORENO, Antonio: Historia de la música española. Siglo XVIII. Madrid, Alianza, 1985.

PAVIA I SIMÓ, Josep: La música en Cataluña en el siglo XVIII: Francesc Valls (1671c.-1747). Barcelona, CSIC, 1997.

RABASSA, Pedro: Guia Para los Principiantes, Que dessean Perfeycionarse en la Compossicion de la Mussica. Ms., Sevilla, 1725c [edn. facsímil (BONASTRE I BERTRAN, Francesc; MARTÍN MORENO, Antonio; y CLIMENT BARBER, José, eds.), Barcelona, Servei de Publicacions de la Universitat Autònoma de Barcelona, 1990], pp.475-476 y 439-440.

ROS PÉREZ, Vicente: Músicos aragoneses en Valencia en el siglo XVIII. Zaragoza, Institución Fernando el Católico, "Tecla Aragonesa, VII”, 2000.

— , “Tomás Ciurana. Una figura del clasicismo valenciano (Peñíscola 1761-Xátiva 1829)”, en Boletín del Centro de Estudios del Maestrazgo, 63, Benicarló, I-III (2000), pp.50-63. 
-, Obras para tecla de Tomás Ciurana (Peñíscola 1761-Xátiva 1829). Estudio y transcripción. Valencia, Diputación Provincial de Valencia, 2001.

SORRIBES CARCELLER, Serafín; y DOÑATE SEBASTIÁN, José María: Órgano de Villarreal. Valencia, Asociación Cabanilles de Amigos del Órgano, col. “Órganos del País Valenciano, VII”, 1980.

VALLS, Francisco: Mapa Armónico Práctico. Breve Resumen De las principales Reglas de Musica. Sacado De Los Mas Classicos Authores Especulativos, y Practicos, Antiguos, y Modernos, Illustrado Con Diferentes Exemplares, Para La mas facil, y segura enseñanza de Muchachos. Ms., Barcelona, 1742a [edn. facsímil (PAVIA I SIMÓ, Josep, ed.), Barcelona, CSIC, col. "Textos Universitarios, 37", 2002], p.71 [fol.16r. del original].

Recibido: 22/04/2012

Aceptado: 21/02/2013 